ARTICLE

\title{
Education and specialist referral of patients with atopic dermatitis
}

R J Green, ${ }^{1}$ MB BCh, DCH, FCP (SA), DTM\&H, MMed, FCCP, PhD, Dip Allergology (SA), DSc;

A Pentz, ${ }^{1} \mathrm{MB}$ ChB, DCH, FCPaed (SA), MMed (Paed), Dip Allergology (SA), Cert Pulmonology (SA) Paed, FCCP;

H F Jordaan, ${ }^{2} \mathrm{MB}$ ChB, MMed (Derm)

${ }^{1}$ Department of Paediatrics and Child Health, Faculty of Health Sciences, University of Pretoria, South Africa

${ }^{2}$ Division of Dermatology, Department of Medicine, Faculty of Medicine and Health Sciences, Stellenbosch University, Cape Town, South Africa

Corresponding author: RJ Green (robin.green@up.ac.za)

Educating patients with atopic dermatitis is an essential and necessary part of therapy and particularly important when young children are involved. Quality of life is seriously impaired if patients or their carers do not understand the chronic and relapsing nature of the disease and how it can be treated.

S Afr Med J 2014;104(10):712. DOI:10.7196/SAMJ.8857

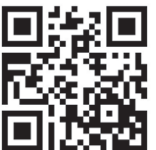

Educating patients with atopic dermatitis $(\mathrm{AD})$ is an essential and unavoidable component of therapy. ${ }^{[1]}$ If the disease involves young children, education of parents is mandatory. Without adequate attention to education, all therapies are futile and the patient is doomed to an impaired quality of life. Practitioners treating patients with $\mathrm{AD}$ must be aware that the disease is one of the most important medical conditions that affects quality of life, ${ }^{[2]}$ which usually involves the entire family. ${ }^{[3]}$

While many of the educational principles centre on an adequate explanation of therapies and their appropriate application and timing, there are a number of factors that must be addressed, including: ${ }^{[4}$

- an explanation of the aetiology and pathology of the disease process

- avoidance of generic (cigarette smoke, irritants) and individual specific (allergens) trigger factors
- attention to skin hygiene and care

- attention to itch prevention (adequate moisturisation, keeping nails short, and avoiding hot bedrooms, woollen clothing, overdressing and soaps)

- an explanation of the chronic and relapsing nature of the disease

- an explanation that all therapies can only treat, not cure, the condition

- an honest discussion about the side-effects of medication

- a discussion about the scientific basis of alternative therapies (homoeopathy, reflexology, naturopathy, acupuncture and herbal therapy). It should suggest that, while such therapies are not grounded by the same evidence required for allopathic medicine, many individuals feel compelled to try them when desperate. Such desperation can usually be overcome by careful attention to skin care and medicine use.

Table 1. Indications for referral to a specialist dermatological service

Immediate (same-day) referral

- If eczema herpeticum (KVE) is suspected*

Urgent referral (within two weeks)

- If the AD is severe and has not responded to optimal topical therapy after one week

- If treatment of bacterially infected AD has failed

Routine (non-urgent) referral

- The diagnosis is/has become uncertain

- $\mathrm{AD}$ on the face has not responded to appropriate treatment

- $\mathrm{AD}$ is associated with severe and recurrent infections

- Contact allergic dermatitis is suspected

- $\mathrm{AD}$ leads to serious social or psychological problems for the child, parent or carer

- The child, parent or carer might benefit from specialist advice regarding treatment

- AD has not been controlled satisfactorily according to a subjective assessment by the child, parent or carer

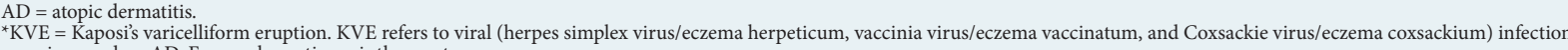
superimposed on $\mathrm{AD}$. Eczema herpeticum is the most common. 
Educational messages need to be repeated frequently. Patients and parents must be given adequate opportunity to raise concerns and ask questions. $\mathrm{AD}$ consultations, even follow-up visits, are usually quite long. Education is greatly aided by providing information leaflets, reputable website addresses and contact details for support groups. ${ }^{[5]}$ The majority of patients with $\mathrm{AD}$ respond to dedicated conservative treatment. Indications for referral to a specialist are listed in Table 1. There are also additional indications. Patients, parents or caregivers with corticosteroid phobia (CSP) should be referred, because it occurs frequently and is not an irrational fear. It describes all types of fear about steroid use. In routine clinical practice, it is not unusual for patients to express fear or anxiety about using topical corticosteroids. Topical CSP, a complex phenomenon, may lead to poor adherence and lack of response.
All patients presenting with erythroderma (dermatitis involving $>90 \%$ of body surface area), any acute flare (spontaneous or precipitated by irritation of the skin), infection, stress or inadequate itch control need referral.

\section{References}

1. Kupfer J, Gieler U, Diepgen TL, et al. Structured education program improves the coping with atopic dermatitis in children and their parents - a multicenter, randomized controlled trial. J Psychosom Res 2010;68(4):353-358. [http://dx.doi.org/10.1016/j.jpsychores.2009.04.014]

2. Holm EA, Wulf HC, Stegmann H, Jemec GB. Life quality assessment among patients with atopic eczema. Br J Dermatol 2006;154:719-725. [http://dx.doi.org/10.1111/j.1365-2133.2005.07050.x] 3. Moore EJ, Williams A, Manias E, Varigos G, Donath S. Eczema workshops reduce severity of childhood atopic eczema. Australas J Dermatol 2009;50(2):100-106. [http://dx.doi.org/10.1111/j.14400960.2009.00515.x]

4. Ogawa S, Uchi H, Fukagawa S. Development of atopic dermatitis-specific communication tools: Interview form and

question and answer brochure. J Dermatol 2007;34(3):164-171. [http://dx.doi.org/10.1111/j.1346-8138.2007.00243.x]

5. Chisolm SS, Taylor SL, Balkrishnan R, Feldman SR. Written action plans: Potential for improving outcomes in children with atopic dermatitis. J Am Acad Dermatol 2008;59(4):677-683. [http://dx.doi. org/10.1016/j.jaad.2008.04.025] 